\title{
Profissionalização dos professores universitários: raízes históricas, problemas atuais
}

Renata Aparecida Belei

Sandra Regina Gimeniz-Paschoal

Edinalva Neves Nascimento

Ana Clara Bortoleto Nery

\section{Resumo}

No Brasil, muitos docentes do ensino superior não possuem formação pedagógica ou didática. O objetivo deste trabalho foi desvelar elementos do processo histórico de profissionalização do ensino superior no País, relacionando-os com problemas atuais encontrados nos processos de ensino-aprendizagem. Foi realizada revisão de literatura, na qual se utilizaram os unitermos "história", "formação", "professores" e "ensino superior". Os resultados apontaram possíveis origens das falhas no processo de ensino-aprendizagem, em decorrência das formas pelas quais se inicia e se estrutura o ensino superior no Brasil, o que sugere reflexões para mudanças, como revisão do método de seleção de professores, equilíbrio da formação didática e pedagógica com a formação específica, formas de ingresso e de atuação docente e incentivo à formação continuada.

Palavras-chave: histórico; profissionalização; ensino superior.

\begin{abstract}
The academical teachers' professionalization: historical roots, current problems

In Brazil, many teachers of higher education do not have pedagogic or didactic formation. This objective of this work was to approach the elements of the historical process of professionalization of the higher education in the country, relating them with the current problems found in the teaching-learning processes. A literature revision was made, in which the terms "history", "formation", "teachers" and "higher education" were used. The results pointed possible origins of flaws in the teaching-learning processes, due to how the higher education in Brazil begins and is structured, what suggests reflections for changes, as a revision of the method of teachers' selection, the balance of didactic and pedagogic with the specific formation, entrance ways, academic performance and incentives to the continuous educational formation.
\end{abstract}

Keywords: historical; professionalization; higher education. 


\section{Introdução}

No Brasil, o ensino superior tem características particulares e apresenta inúmeros problemas, como deterioração salarial, desprestígio profissional e precariedade da formação docente (Godoy, 1983; Schwartzman, 1988). Atualmente são vários os cursos ministrados por professores de formação diferenciada, com trajetórias diferentes, mas com uma característica que acompanha a maioria dos docentes: formação pedagógica ou didática ausente ou precária.

Encontram-se nessa situação enfermeiros, médicos, advogados, engenheiros e outros profissionais que passaram a ocupar o cargo de docente e que almejam repassar suas habilidades profissionais para a carreira de professor. Muitos têm êxito, mas a grande maioria segue a trajetória acadêmica driblando os obstáculos e dificuldades inerentes ao desenvolvimento do processo de ensino-aprendizagem.

Nos cursos de graduação desses profissionais, de forma geral, não são contemplados aspectos pedagógicos mínimos necessários à carreira docente (Pimenta, Anastasiou, 2002). Como os cursos de graduação se dividem em bacharelado e licenciatura, somente neste segundo caso há preocupação com a formação do professor, ainda que mínima e muitas vezes desarticulada com a formação específica da área do curso.

Acontece que muitos bacharéis se tornam professores da educação superior. Nesses casos, as disciplinas de metodologia do ensino superior ou de didática ficam restritas a cursos de pós-graduação e, infelizmente, algumas vezes, são optativas. O próprio processo seletivo de muitas faculdades e universidades exigem apenas titulação e experiência profissional, mas não específica para o ensino, não sendo avaliada a formação pedagógica dos futuros docentes do ensino superior, como ocorre, com freqüência, nos cursos da área da saúde, dos quais nos ocupamos em nossas pesquisas.

Nas últimas décadas muito se falou sobre mudanças na formação dos profissionais e sobre a necessidade de se reverem programas, currículos e projetos pedagógicos (Moreira, Silva, 2000; Sena, 2000; Sacristãn, Pérez Gomes, 2000). Entretanto, nem sempre os problemas encontrados no processo de ensino são decorrentes de negligência ou da falta de mudanças curriculares.

Belei (2003) analisou a ocorrência de acidente com material biológico num curso de enfermagem e verificou que, mesmo com a reforma curricular e com a implantação de um currículo integrado, o processo de ensino sobre o tema ainda apresentava falhas, permitindo que o risco de acidente se mantivesse elevado entre os acadêmicos.

Segundo Ramos e Júnior (1992), são muitas as causas da decadência do ensino universitário específico para os cursos da área da saúde, destacando-se o erro pedagógico, as muitas responsabilidades do profissional/professor, o despreparo humanístico, vocacional e psicológico do docente e do aluno, o número excessivo de cursos, a desproporção numérica docente-aluno, os recursos humanos inadequados de docentes e pessoal técnico, etc.

Um ponto importante também apontado pelos autores é a supervalorização do curso de pós-graduação em detrimento da graduação. Deixam-se para depois questões extremamente relevantes para a formação, resultando num profissional incompleto, sem preparo técnico-científico e até psicológico, não condizente com o perfil exigido pela sociedade. E de onde vêm todos estes problemas?

De acordo com Nóvoa (1992), uma das formas de se compreender os problemas atuais relacionados com o processo de ensino-aprendizagem é procurar entender o processo histórico de profissionalização, pois daí se originaram algumas características que se mostram presentes ainda hoje no processo de trabalho dos profissionais do ensino superior.

Logo, o objetivo deste trabalho foi buscar as raízes históricas da problemática acima apontada, de forma não exaustiva, nos estudos desenvolvido na área de história da formação dos professores universitários no Brasil, relacionando-as com a situação atual do ensino nos cursos de graduação. O recorte utilizado preocupa-se com a formação nos bacharelados, ainda que não encontremos estudos específicos sobre esta modalidade da educação superior. Para isto, foi realizado um levantamento bibliográfico utilizando-se os seguintes unitermos: "história", "formação", "professores", "ensino superior".

\section{Características da criacão dos cursos superiores no Brasil}

Segundo Schwartzman (1982), no Brasil, até o início da República, a produção 
científica apresentou características muito precárias, com a criação de centros de estudos e escolas burocratizadas, os quais dependiam totalmente do Império, de onde provinham os recursos e as determinações referentes aos modelos intelectuais e institucionais, principalmente em São Paulo, Rio de Janeiro, Paraná e Bahia.

As atividades científicas não eram valorizadas e nem recebiam investimentos governamentais, o que se refletia nas ciências e na educação superior, principiantes no Brasil. O século 17 marcou o início da institucionalização da ciência européia, culminando com a síntese newtoniana que estabeleceu um modelo intelectual a ser seguido, um paradigma que permitiu distinguir com clareza o que devia ou não ser entendido como ciência (Schwartzman, 1982).

Os trabalhos dos naturalistas destacaram-se no século 18, descrevendo e desenvolvendo sistemas de classificação de plantas, animais e fenômenos geológicos, quando, também, foram lançadas as bases iniciais das teorias evolucionistas e Lavoisier deu inicio à química moderna. Avançaram os estudos da matéria, da eletricidade, do magnetismo e dos fenômenos de calor e energia (Masetto, 2002).

Em Portugal, o jugo clerical da Contra-Reforma e da Inquisição isolava o País, impedindo-o de acompanhar a evolução da ciência. Somente com a Reforma Pombalina rompeu-se esse isolamento, mas não de modo suficiente para se estabelecer o início de uma comunidade científica como ocorrera em outros países (Schwartzman, 1982). Essa situação causou fortes repercussões no Brasil, colônia portuguesa.

No período colonial não existia ensino superior no Brasil, salvo para as carreiras eclesiásticas. Foi um período marcado por faculdades isoladas que se destinavam apenas à formação e à transmissão de conhecimento para alguns poucos privilegiados (Cavalcanti, 2004, p. 227). Nessa época, a escola era extremamente elitizada e sem foco no processo de ensino-aprendizagem (Masetto, 2002).

A instauração de uma universidade somente foi cogitada no período final desse ciclo, quando do término dos movimentos que causaram a reforma da monarquia e, logo depois, o início do processo de independência. Essa iniciativa partiu de José Bonifácio de Andrada e Silva (1763-1838), saído da universidade pombalina no final do século 18 (Cavalcanti, 2004).

Com a República surgiram novas prioridades, novos pólos de crescimento e novas preocupações que se voltaram, principalmente, para a agricultura, a saúde pública e os recursos minerais.

A mudança do foco da pesquisa, que de acadêmica passou a ser mais aplicada, favoreceu a criação de institutos de pesquisa, como o Oswaldo Cruz. Entretanto, as transformações voltadas para uma formação técnico-profissional que atendesse às necessidades da nascente industrialização e ao crescimento da agricultura, ainda não permitiriam um equacionamento satisfatório do problema da implantação da ciência moderna no Brasil (Stepan, 1975; Cavalcanti, 2004).

Inicialmente, os temas eram discutidos pelos cientistas de acordo com os princípios da ciência européia do século 19, resumindo-se à história natural taxonômica, à astronomia anterior à astrofísica, à medicina bacteriana, às geociências de tipo exploratório e descritivo, à química tradicional. $\mathrm{O}$ ensino não era direcionado para abrir novas fronteiras e para descobrimentos importantes (Schwartzman, 1982). Apenas eram repassados os conhecimentos descobertos no passado.

Todos os conhecimentos importantes provinham de pesquisadores estrangeiros que aqui se radicavam ou, em menor grau, de brasileiros formados no exterior. Tudo o que era relacionado com a ciência se firmou fora do sistema de educação superior, que não tinha nem lugar para a pesquisa científica. Somente em poucos lugares havia desenvolvimento das ciências, como no Observatório Nacional, no Instituto Agronômico e no Instituto de Manguinhos (Schwartzman, 1982).

Na virada do século 20, havia no Brasil apenas uma instituição diretamente pertencente ao âmbito universitário, na qual se comprova a existência de espírito científico e gosto pela experimentação. Tal exceção, segundo Schwartzman (1982), era a Escola de Medicina da Bahia.

Na França, o sistema de educação superior foi reformado a partir do período napoleônico. Foram estabelecidos dois tipos de instituições: de um lado, as écoles, escolas especializadas para formação de uma elite técnica e administrativa; de outro, as facultés, estabelecimentos de ensino 
para formação de professores ou profissionais liberais, sendo controladas e fiscalizadas pelo poder central (Fernandes, 2002).

A estrutura rígida do sistema napoleônico fez com que prevalecesse na ciência um espírito conservador, tal como ocorreu em vários outros aspectos da vida francesa. Sem dúvida, esse modelo inspirou a estrutura oficial de educação superior no Brasil, voltada para a profissionalização, o que supervalorizou as ciências exatas e tecnológicas em detrimento da filosofia, teologia e ciências humanas (Masetto, 2002).

Nas primeiras escolas do Brasil, os currículos eram seriados, com programas fechados e disciplinas destinadas a formar professores competentes em uma determinada área ou especialidade. Já vigorava o sistema de aprendizado no qual o docente deveria transmitir aquilo que sabia, para o aluno que nada conhecia. E o resultado da aprendizagem era avaliado pelo mesmo profissional, que dizia se o aluno estava apto ou não para exercer determinada profissão. Em caso positivo, o aluno recebia um diploma que certificava sua competência profissional. Caso contrário, repetia o curso (Masetto, 2002).

$\mathrm{Na}$ época, aprender era conseguir repetir o que o professor tinha ensinado e, quando a avaliação revelava um fracasso nesse sentido, a culpa era totalmente do aluno. Jamais era questionado se o professor era um bom profissional. Não existia discussão sobre sua formação e, conseqüentemente, sobre o seu preparo para o trabalho na docência.

Os cursos superiores procuravam profissionais que tinham sucesso em suas atividades profissionais, convidando-os a ensinarem seus alunos a serem tão bons quanto eles. Praticamente se exigia o bacharelado e as competências profissionais, pois "quem sabe, automaticamente, sabe ensinar” (Masetto, 2002, p. 11).

Foi somente a partir da metade da década de 20 que os membros das associações brasileiras de educação e de ciência começaram a debater as funções da universidade, inclusive em relação ao seu papel na comunidade, apresentado na forma de projetos de extensão.

$\mathrm{Na}$ década de 30 foram realizadas mudanças importantes, impulsionadas pela reforma da Universidade do Rio de Janeiro, elaboração do Estatuto das Universidades Brasileiras (1933), assim como a fundação das universidades de São Paulo (1934) e do Distrito Federal (1935). Todos esses fatores impulsionaram a produção intelectual no País, sendo vista como um foro privilegiado de transmissão e de produção de conhecimentos, bem como de ensino de ciência e de trabalho científico.

\section{Expansão do ensino superior}

Com a fundação dessas universidades houve um incentivo ao desenvolvimento das humanidades e, a partir da década de 70, a expansão do ensino superior processou-se de forma muito acelerada, fora dos grandes centros urbanos e com o predomínio da iniciativa privada que foi apoiada por grandes empresários (Schwartzman, 1991). No período de 1962-1973, o número de estudantes universitários pulou de 100 mil para 800 mil e os do ensino superior privado passou de $40 \mathrm{mil}$ para $500 \mathrm{mil}$ (Silva Junior, Sguissardi, 2001).

O ensino superior privado, segundo Silva Junior e Sguissardi (2001), expandiuse, organizou-se e tornou-se hegemônico no nível administrativo, determinando muitas das medidas políticas e de legislação educacional nas esferas do Executivo e Legislativo. Por esta razão, esse ramo empresarial continua organizado e sólido, tanto na economia como na política brasileira.

Dados da Unesco demonstram que o número de professores universitários, entre 1950 e 1992, saltou de 25 mil para 1 milhão, ou seja, o aumento foi de 40 vezes. No entanto, são quase todos professores improvisados, sem preparo para desenvolver a função de pesquisador e sem formação pedagógica (Pimenta, Anastasiou, 2002).

Atualmente discute-se o processo de ensino-aprendizagem nos cursos de ensino superior da área da saúde e destaca-se a necessidade do retorno social, mas os docentes ainda não apresentam formação e recursos suficientes para atender à demanda de ensino, pesquisa e extensão.

Segundo Cunha (1982), hoje existem sete vezes mais estudantes e instituições de ensino no País do que na década de 30. Conseqüentemente, houve um crescimento do número de tarefas dos docentes, mas estes não apresentam mecanismos para darem conta desta demanda. 
Cobra-se do processo de ensino-aprendizagem que exista enfoque nas áreas do conhecimento, do relacionamento afetivoemocional, das habilidades, das atitudes e dos valores. Entretanto, como cobrar tais particularidades de um educador que não teve formação para o ensino? Como cobrar de um profissional que não foi preparado para mediar o processo de aprendizagem?

Rossit e Zuliani (2004) relatam que o sistema educacional brasileiro vem acumulando, ao longo de muitos anos, histórias de fracasso no processo de ensinoaprendizagem. Culturalmente, esta derrota é delegada às características inatas do aluno e às condições do ambiente, mas muito se deve à maneira como os educadores atuam, aos métodos que escolhem, às atitudes que adotam no cotidiano de trabalho e, também, à impossibilidade de utilização de métodos apropriados, capazes de oferecer um ensino que promova uma aprendizagem efetiva.

Coolahan (2002) afirma que na carreira do docente do ensino superior se interpõem inúmeros obstáculos, principalmente os de ordem didática e pedagógica, em virtude do contexto mundial, no qual a educação ainda necessita de muito mais investimentos.

O curso superior é o único que não requer uma formação específica para o magistério. $\mathrm{O}$ ensino fundamental e o médio exigem formação superior em pedagogia e/ou licenciatura; no entanto, para lecionar no curso superior basta ser graduado em qualquer especialidade. As instituições de ensino têm procurado mudanças, fazendo concursos públicos nos quais se exige mestrado e doutorado, mas ainda não oferecem preparação específica para o magistério superior (Cunha, 1985, 2004).

Não se exige formação pedagógica para ingressar na carreira docente, mas a maioria dos trabalhos que questionam o processo de ensino-aprendizagem é de docentes universitários. Exige-se experiência em docência, mas esta é avaliada usualmente pelo tempo já dedicado à função, ou seja, uma análise quantitativa e superficial.

Pede-se também graduação na área específica e titulação de especialista, mestre ou doutor, subentendendo-se que quem é formado sabe formar novos profissionais. Isto nos remete ao pensamento marcante de anos atrás, quando se acreditava que para ser um bom professor bastaria existir a vocação (Fernandes, 2002).
Cunha (2002, p. 83) afirma que a vocação é um assunto bastante complexo e que parece ser mais influenciada pelo ambiente social (e relações estabelecidas neste meio) do que por características naturais. Um ambiente bem preparado pode ajudar na formação de um bom docente. Mas será que as instituições propiciam um ambiente adequado para a capacitação do docente? E, quando capacitado, há condições para o desenvolvimento de uma prática de ensino apropriada, amparada por conhecimento, discussão e reflexão?

Nóvoa (1991) sugere que o aprendizado dos professores deva ser realizado na prática cotidiana e coletivamente, de forma a construir o elo entre ensino, pesquisa e extensão. Dessa forma, será construído o ensino pelos próprios professores e na perspectiva da produção de conhecimento, que será aplicado nestas duas vertentes, ou seja, pesquisa e extensão.

Infelizmente não é esta a realidade brasileira. O preparo adequado dos docentes ficou em segundo plano devido à grande demanda por esses profissionais e por interesses econômicos.

\section{Avaliação da aprendizagem no ensino superior}

Para Pimenta e Anastasiou (2002), geralmente não se exige formação pedagógica na docência do ensino superior porque, aparentemente, é suficiente o domínio de conhecimentos específicos, pois o que valoriza o docente universitário é a pesquisa e/ou o exercício profissional no campo. Deste ponto de vista, todo professor automaticamente é aquele que ensina, isto é, dispõe os conhecimentos aos alunos.

$\mathrm{Na}$ maioria das instituições de ensino superior, os profissionais são experientes, titulados em diversas áreas, desenvolvem pesquisas em áreas específicas, mas são totalmente despreparados para o ensino. Muitos não têm conhecimento científico do que seja e do que precisa o processo de ensino-aprendizagem (Wahrhaftig, Ferrazza, Raupp, 2001).

E essa situação é um problema do professor e/ou das instituições de ensino e governamentais. Deve-se lembrar que, como não há formação específica para professor universitário, a busca é individual, mediante cursos, congressos, pósgraduação, etc. Entretanto, o incentivo 
(incluindo oferecimento de condições reais para o docente operacionalizar suas ações voltadas para o processo de ensino-aprendizagem, bem como a cobrança e a valorização do docente) deve partir também da instituição à qual ele está vinculado, assim como dos órgãos federais, como o Ministério da Educação (MEC), a Coordenação de Aperfeiçoamento de Pessoal de Nível Superior (Capes) e o Conselho Nacional de Desenvolvimento Científico e Tecnológico (CNPq).

Ressaltam Pimenta e Anastasiou (2002, p. 39) que:

\section{[...] as necessidades atuais apontam para uma formação mais voltada para um cam- po específico e pedagógico para o docen- te de curso superior, preparando-o para participar de processos curriculares, ad- ministrativos, gerenciais, políticos, finan- ceiros, etc.}

Sabe-se que o grau de qualificação é um fato-chave no fomento da qualidade em qualquer profissão - especialmente na educação que experimenta constante mudança. Entretanto, para Silva Junior e Sguissardi (2001), deve-se dar preferência à formação específica para o processo educacional, em primeiro plano.

De acordo com Pimenta e Anastasiou (2002), a legislação contempla esses aspectos falhos no ensino superior, apontando caminhos que amenizam estes problemas. A Lei de Diretrizes e Bases da Educação Nacional (Lei no 9.394/96) e o Decreto $\mathrm{n}^{\circ} 2.207 / 97$, que regulamenta o Sistema Federal de Ensino, exigem preparação pedagógica para o exercício da docência no ensino superior. Detalhando, estabelecem que, no segundo ano de vigência, a instituição de ensino deve contar com 15\% dos docentes com titulação stricto sensu, dos quais 5\% devem ser doutores; no quinto ano os valores se modificam para $25 \%$, dos quais $10 \%$ seriam doutores; e, no oitavo ano, essa proporção passa para $1 / 3$, dos quais $15 \%$ seriam doutores. Entretanto, estes aspectos exigidos pela LDB garantem formação específica para o processo educacional?

Atualmente, a Lei $\mathrm{n}^{\circ}$ 9.394/96 estabelece que a docência no ensino superior será preparada nos programas de pósgraduação stricto sensu, mas a competência docente é mensurada pelos resultados dos alunos na avaliação (Pimenta,
Anastasiou, 2002). Essa estratégia do governo pode até ser uma forma de mensuração, mas, para o docente, esse tipo de resultado não lhe agrega valor, pois não serve de critério para, por exemplo, conceder um financiamento para ações/pesquisas relativas ao ensino.

A Lei $n^{\circ}$ 9.394/96 não concebe a docência como um processo de formação, mas sim como preparação titulada para o exercício do magistério superior, que será realizada prioritariamente (não exclusivamente) em pós-graduação stricto sensu. Por outro lado, há um aumento na oferta de lato sensu ou de disciplinas de Metodologia do Ensino Superior ou Didática do Ensino Superior para auxiliar na formação docente. Porém, ainda que tais disciplinas pudessem ajudar na resolução do problema, elas não são uma exigência da legislação (Pimenta, Anastasiou, 2002, p. 41).

Para Ramos-Cerqueira e Lima (2002), o profissional que ingressa na carreira docente encontra um caminho difícil. Ele depara-se com departamentos estruturados há muitos anos, com disciplinas já organizadas, métodos estabelecidos, rotinas implantadas e é colocado nas engrenagens de um processo de trabalho já existente. É comum o docente iniciar sua carreira sem o recebimento de orientação quanto a processos de planejamento e métodos de ensino ou de avaliação, orientação essa que lhe permitiria refletir sobre a própria práxis. Ele necessita atuar em sua disciplina, em seu departamento, o que o mantém isolado dos demais professores e, muitas vezes, distante da prática. Porém, precisa demonstrar que detém todo o conhecimento, transmitindo-o aos estudantes, como no modelo jesuítico, no qual os padres representavam o total poder no setor educacional.

Neste âmbito, acabam sendo realizadas experiências como a construção coletiva de projetos pedagógicos institucionais e de revisões metodológicas na direção de um processo dialético de construção do conhecimento, que se evidencia em atividades de ensino com pesquisa, ensino por projetos, etc. Nessa realidade, os professores e alunos assumem o papel de condutores do processo de fazer da universidade um espaço de construção de cidadania, de resolução das questões sociais, de formação profissional qualificada e atualizada (Galasso, 2002). 
As raízes históricas dos problemas atuais estão sendo superadas em algumas instituições brasileiras. Entretanto, iniciativas como mudança curricular, adoção de metodologias de ensino-aprendizagem baseadas em problematização, integração de conteúdos e de docentes, inclusão do aluno na seleção de conteúdos e na busca de conhecimentos, descentralização do ensino, preparo didático-pedagógico dos docentes, discussões interdisciplinares de formas de avaliação docente/aluno, dentre outras, são reduzidas e localizadas e não chegam a mudar o quadro geral que este estudo tenta mostrar, mas servem como exemplos de caminhos promissores para a superação das marcas históricas.

Os docentes devem rever sua forma de organização pedagógica, realizada geralmente de forma isolada, sem vínculos com outros profissionais ou com diferentes instituições e áreas, sem apoio pedagógico que auxilie sua práxis. Oficinas didático-pedagógicas podem ajudar na melhoria da prática docente, mas esforços individuais e coletivos nessa busca devem ser incentivados.

São necessárias articulações entre os docentes para modificar normas e rotinas relacionadas com a seleção de profissionais da educação, sua avaliação profissional e promoção. Por que vincular a ascensão apenas à titulação e ao tempo de serviço? Por que não conceder aumento salarial ou de status com base na elaboração ou implantação de metas/ ações voltadas para a melhoria de práticas pedagógicas que auxiliem o processo de ensino e aprendizagem?

Os profissionais do ensino superior devem possuir conhecimentos dos aspectos psicológicos relacionados com a formação, devendo preocupar-se não apenas com questões curriculares e pedagógicas, mas também com o modelo de relação professor-aluno, com aspectos psicológicos do comportamento de aprender (Gaillard, Krishna, Waast, 1997; OECD, 2000; Ramos-Cerqueira, Lima, 2002).

Os docentes do ensino superior precisam tomar consciência da responsabilidade pela formação de futuros profissionais, atuando ativamente por mudanças, cobrando das instituições de ensino o incentivo para participarem de cursos específicos da área de educação, mantendo relações contínuas com temas pedagógicos e educacionais, principalmente para os que atuam em cursos não pertencentes à área da educação.

É importante destacar também as responsabilidades dos profissionais atuantes em órgãos governamentais municipais, estaduais e federais. Esses profissionais deveriam exercer ativamente o papel de incentivadores de mudanças, elaborando leis específicas, priorizando recursos para a capacitação e para incentivar a produção, destinando recursos à educação superior. Mesmo o papel dos reitores de universidade deveria ser ampliado, especialmente no caso das públicas, sendo permitida uma atuação mais decisiva junto ao Legislativo. Dessa forma, o peso de superar os equívocos da história no contexto atual do ensino superior não recairia apenas sobre o docente.

\section{Conclusão}

A situação escolar brasileira e os problemas que a agravam têm seus alicerces nas instituições de ensino superior, onde se formam os docentes, os planejadores e os administradores do sistema. Se não existir uma capacitação específica, além do diploma de bacharel e dos cursos de mestrado e doutorado, os docentes continuarão formando outros profissionais (e docentes) da mesma forma como foram ensinados.

O ensino na universidade constitui um processo de busca, de construção científica e de crítica do conhecimento produzido, inclusive de análise crítica do desempenho desse conhecimento na construção da sociedade. Por isso, as falhas na formação de professores para o ensino superior devem ser consideradas como um problema que necessita de profunda reflexão e de iniciativas para a mudança.

Todas as instituições de ensino superior devem preocupar-se com a qualidade dos resultados do seu ensino, que reproduzirá a importância da preparação política, científica e pedagógica de seus docentes e se traduzirá numa preparação mais condizente com as necessidades atuais dos discentes/futuros profissionais, em especial dos futuros docentes que irão se tornar os que planejam e administram o próprio sistema educacional.

Educadores e estudiosos que estiverem em qualquer posto, desde o da sua própria sala de aula ou no contexto de 
ensino a distância, num colegiado da instituição acadêmica, num posto do governo municipal, estadual ou federal, num cargo legislativo, etc., devem promover discussões e potencializar mudanças no processo de trabalho dos docentes e na formação dos discentes do ensino superior, com vista a incluir a abordagem de elementos relevantes para o processo educacional, para se construir uma pedagogia diferenciada que valorize todos os protagonistas do processo, que privilegie a formação do cidadão e a construção de competências.
Todo o contexto histórico da formação da comunidade científica brasileira pode também mostrar seus reflexos na atuação profissional dos professores universitários, ainda com carências didáticas e metodológicas em seu trabalho. É importante que os educadores do ensino superior procurem compreender esta relação e ousem operacionalizar mudanças, unindo esforços para buscar soluções para problemas atuais encontrados na maioria das instituições do País, que podem ser fruto da história da formação de professores no Brasil.

\section{Referências bibliográficas}

BELEI, R. A. Enfermagem e acidente com material biológico: aspectos teóricos da formação e opiniões de docentes e discentes. 2003. 243 f. Dissertação (Mestrado em Educação) - Faculdade de Filosofia e Ciências, Universidade Estadual Paulista Júlio de Mesquita Filho, Marília, 2003.

CAVALCANTI, V. R. S. Mudanças do ensino superior brasileiro e o novo perfil dos sujeitos educadores. Revista de Educação Unisinos, v. 8, n. 14, p. 223-242, 2004.

COOLAHAN, J. Teacher education and the teaching career in era of lifelong learning. Paris: OECD, 2002. (OECD Education Working Papers, EDU/WKP (2002) 2 ). Disponível em: <www.oecd.org/edu/workingpapers $>$.

CUNHA, L. A. A universidade crítica: o ensino superior na República populista. Rio de Janeiro: Francisco Alves, 1982.

CUNHA, L. A. A universidade temporã: o ensino superior da colônia à Era de Vargas. Rio de Janeiro: Francisco Alves, 1985.

CUNHA, L. A. Desenvolvimento desigual e combinado no ensino superior: Estado e mercado. Revista Educação e Sociedade, v. 25, n. 88, p. 795-817, 2004.

CUNHA, M. I. O bom professor e sua prática. In: MASETTO, M. T. Docência na Universidade. Campinas: Papirus, 2002. p. 27-38.

FERNANDES, C. M. B. A formação do professor universitário: tarefa de quem? In: MASETTO, M. T. Docência na universidade. Campinas: Papirus, 2002. p. 95-112.

GAILLARD, J.; KRISHNA, V. V.; WAAST, R. Scientific communities in the developing world. Thousands Oaks, Califórnia: Sage Publications, 1997.

GALASSO, R. Informática na educação: perspectivas de inclusão. Mundo da Saúde, v. 26, n. 3, p.392, 2002.

GODOY, A. S. Professor universitário da área agronômica: o problema da formação pedagógica. 1983. 193 f. Dissertação (Mestrado em Educação) - Faculdade de Educação, Universidade de São Paulo, São Paulo, 1983.

MASETTO, M. T. Docência na universidade. Campinas: Papirus, 2002. p. 9-26. 
MOREIRA, A. F.; SILVA, T. T. Sociologia e teoria crítica ao currículo: uma introdução. In: . Currículo, cultura e sociedade. São Paulo: Cortez, 2000. p. 7-38.

NÓVOA, A (Org.). Os professores e a sua formação. Lisboa: Dom Quixote, 1992.

NÓVOA, A. Concepções e práticas de formação contínua de professores. Portugal: Universidade de Aveiro, 1991.

OECD. What works in innovation in education motivating students for lifelong learning. Paris, 2000.

PIMENTA, S. G.; ANASTASIOU, L. G. C. Docência no ensino superior. São Paulo: Cortez, 2002.

RAMOS JUNIOR, J. Os erros e as incongruências do ensino médico no Brasil. Acta Oncológica Brasileira, v. 12, n. 1, p. 35-45, 1992.

RAMOS-CERQUEIRA, A .T. A.; LIMA, M. C. P. A formação da identidade do médico: implicações para o ensino de graduação em medicina. Interface: comunidade, saúde e educação, v. 6, n.11, p. 107-116, 2002.

ROSSIT, R.; ZULIANI, G. Procedimentos de ensino na perspectiva da análise comportamental. In: ENCONTRO DA ABPMC, 13; ENCONTRO INTERNACIONAL DA ABA, 2. 2004, Campinas. Anais....Campinas, 2004.

SACRISTÃN, J. G.; PÉREZ GOMEZ, A. I. Compreender e transformar o ensino. In: . O currículo: os conteúdos do ensino ou uma análise prática. Porto Alegre, 2000. p. 119-148.

SCHWARTZMAN, S. A space for science the development of the scientific community in Brazil. University Park: Pennsylvania State University Press, 1991.

A pesquisa científica no Brasil: matrizes culturais e institucionais. Pesquisa Médica, v. 1, p. 137-160, 1982.

. Brazil: opportunity and crisis in higher education. Higher Education, v. 17, n. 1, p. 99-119, 1988.

SENA, R. R. Novas tecnologias de ensino: desafio e potencialidade. Olho Mágico, v. 6, n. 21, p. 7-8, 2000.

SILVA JUNIOR; J. R.; SGUISSARDI, V. Novas faces da educação superior no Brasil. São Paulo: Cortez, 2001.

STEPAN, N. Beginings of Brazilian Science: Oswaldo Cruz Medical Research and Policy, New York: Science History Publications, 1975.

WAHRHAFTIG, R.; FERRAZZA, A. M.; RAUPP, M. Portas abertas para a educação superior. Curitiba: Fundação Universidade Eletrônica do Paraná, 2001.

Renata Aparecida Belei, doutoranda em Educação pela Universidade Estadual Paulista "Júlio de Mesquita Filho" (Unesp/Campus de Marília-SP).

rabelei@yahoo.com.br;ccihhurnp@uel.br.

Sandra Regina Gimeniz-Paschoal, doutora em Psicologia pela Universidade de São Paulo (USP), é docente do curso de Fonoaudiologia e do Programa de Pós-Graduação 
em Educação da Universidade Estadual Paulista "Júlio de Mesquita Filho" (Unesp/

Campus de Marília-SP)

sandragp@marilia.unesp.br

Edinalva Neves Nascimento, doutoranda em Educação pela Universidade Estadual Paulista "Júlio de Mesquita Filho" (Unesp/Campus de Marília-SP).

ediquata@flash.tv.br; edinalva@marilia.unesp.br

Ana Clara Bortoleto Nery, doutora em Educação pela Faculdade de Educação da Universidade de São Paulo (Feusp), é docente do curso de Pedagogia e do Programa de Pós-Graduação em Educação da Universidade Estadual Paulista "Júlio de Mesquita Filho" (Unesp/Campus de Marília-SP).

anacnery@marilia.unesp.br.

Recebido em 30 de janeiro de 2006.

Aprovado em 17 de novembro de 2006. 